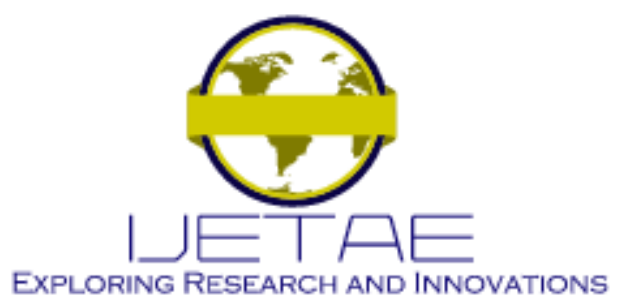

International Journal of Emerging Technology and Advanced Engineering

Website: www.ijetae.com (E-ISSN 2250-2459, Scopus Indexed, ISO 9001:2008 Certified Journal, Volume 11, Issue 07, July 2021)

Manuscript Received: 05 June 2021, Received in Revised form: 08 July 2021, Accepted: 12 July 2021

DOI: 10.46338/ijetae0721_03

\title{
A Simulation Study of Noise Behavior in Basic Current Mirror using CNTFET and MOSFET
}

\author{
Roberto Marani ${ }^{1}$, Anna Gina Perri ${ }^{2}$ \\ ${ }^{I}$ National Research Council of Italy (CNR), Institute of Intelligent Industrial Technologies and Systems for Advanced \\ Manufacturing (STIIMA), Bari, via Amendola 122 D/O, 70126 Bari, Italy \\ ${ }^{2}$ Electronic Devices Laboratory, Department of Electrical and Information Engineering, Polytechnic University of Bari, \\ via E. Orabona 4, 70125 Bari, Italy
}

\begin{abstract}
We present a aimulation study of noise behavior in basic current mirror using CNTFET and MOSFET, obtaining that the output noise current is always higher for the CNTFET than for the MOS device.
\end{abstract}

Keywords - CNTFET, MOSFET, Modelling, Current Mirror Design, Advanced Design System (ADS).

\section{INTRODUCTION}

CNTFET is a new kind of molecular device, using a carbon nanotube as channel [1-7].

Among carbon nanotube FETs, for conventional CNTFET [8-9], we have already proposed a compact, semi-empirical model [3-10], implemented both in SPICE and in Verilog-A [11], in order to carry out static and dynamic analysis of A/D circuits [12-18].

In this paper we present a simulation study of a basic current mirror based on CNTFET in order to compare it with the same using MOS device. To have comparable results, we refer to a conventional CNTFET and a MOSFET in $32 \mathrm{~nm}$ technology.

The simulation results allow to show the output I-V curves, the output differential conductances at various output voltages, the output admittance at various frequencies and the spectral density of output noise current.

For reference current of $1 \mu \mathrm{A}$ and $10 \mu \mathrm{A}$ the output static and dynamic characteristics are better in the case of CNTFET, but the output noise current is always higher for the CNTFET than for the MOS device.

\section{A REVIEW OF OUR CNTFET MODEL}

An exhaustive description of our I-V CNTFET model is in [14-18], and therefore the reader is requested to consult them.

In this Section we describe the main equations on which is based our CNTFET model.

\section{A. I-V model}

Our model is based on a work of A. Raychowdhury et al. [19] and on the following improvements introduced by F. Prégaldiny et al. [20-21].

With the hypothesis that each sub-band decreases by the same quantity along the whole channel length, the total drain current can be expressed as [22]:

$$
\mathrm{I}_{\mathrm{DS}}=\frac{4 \mathrm{qkT}}{\mathrm{h}} \sum_{\mathrm{p}}\left[\ln \left(1+\exp \xi_{\mathrm{Sp}}\right)-\ln \left(1+\exp \xi_{\mathrm{Dp}}\right)\right]
$$

where $\mathrm{k}$ is the Boltzmann constant, $\mathrm{T}$ is the absolute temperature, $\mathrm{h}$ is the Planck constant, $\mathrm{p}$ is the number of sub-bands, while $\xi_{\mathrm{Sp}}$ and $\xi_{\mathrm{Dp}}$, depending on temperature through the sub-bands energy gap, and the surface potential, $\mathrm{V}_{\mathrm{CNT}}$, have the expressions reported in [3-4].

\section{B. $C$-V model}

An exhaustive description of our $\mathrm{C}-\mathrm{V}$ model is widely described in our References [3-4] and therefore the reader is requested to consult them, in which the following expressions of quantum capacitances $\mathrm{C}_{\mathrm{GD}}$ and $\mathrm{C}_{\mathrm{GS}}$ are explained:

$$
\left\{\begin{array}{l}
\mathrm{C}_{\mathrm{GD}}=\mathrm{q} \sum_{\mathrm{p}} \frac{\partial \mathrm{n}_{\mathrm{Dp}}}{\partial \mathrm{V}_{\mathrm{GS}}}=\mathrm{q} \sum_{\mathrm{p}} \frac{\partial \mathrm{n}_{\mathrm{Dp}}}{\partial \xi_{\mathrm{Dp}}} \frac{\partial \xi_{\mathrm{Dp}}}{\partial \mathrm{V}_{\mathrm{CNT}}} \frac{\partial \mathrm{V}_{\mathrm{CNT}}}{\partial \mathrm{V}_{\mathrm{GS}}} \\
\mathrm{C}_{\mathrm{GS}}=\mathrm{q} \sum_{\mathrm{p}} \frac{\partial \mathrm{n}_{\mathrm{Sp}}}{\partial \mathrm{V}_{\mathrm{GS}}}=\mathrm{q} \sum_{\mathrm{p}} \frac{\partial \mathrm{n}_{\mathrm{Sp}}}{\partial \xi_{\mathrm{Sp}}} \frac{\partial \xi_{\mathrm{Sp}}}{\partial \mathrm{V}_{\mathrm{CNT}}} \frac{\partial \mathrm{V}_{\mathrm{CNT}}}{\partial \mathrm{V}_{\mathrm{GS}}}
\end{array}\right.
$$

To estimate parasitic capacitances and inductances and the drain and source contact resistances, we have used an empirical method [23-24], that requires the extraction of the previous parasitic elements comparing the device characteristics with the measured ones. This procedure is widely described in our previous papers [3-4], where all elements of the equivalent circuit have bene determined. 


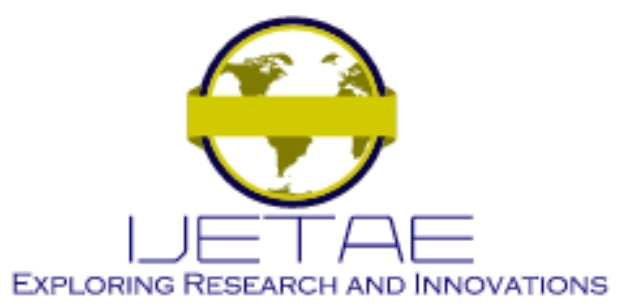

International Journal of Emerging Technology and Advanced Engineering Website: www.ijetae.com (E-ISSN 2250-2459, Scopus Indexed, ISO 9001:2008 Certified Journal, Volume 11, Issue 07, July 2021)

Fig. 1 shows our model, while Fig. 2 its symbol.

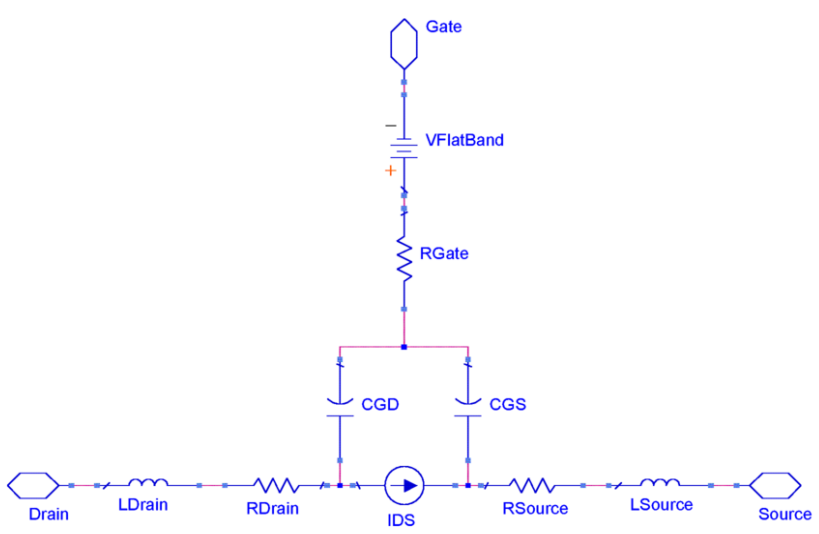

Figure 1. Equivalent circuit of a n-type CNTFET.

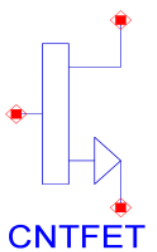

Figure 2. CNTFET symbol.

\section{MOSFET model}

For the MOSFET model we use the BSIM4 model of ADS library [25].

Fig. 3 shows n-channel MOSFET model.

The diodes are associated with the $\mathrm{p}-\mathrm{n}+$ junctions between the substrate, of $\mathrm{p}$ type, and the ohmic contacts; $\mathrm{C}_{\mathrm{SB}}$ and $\mathrm{C}_{\mathrm{DB}}$ are the transition capacities associated with the reverse bias of the corresponding $p-n$ junctions (sourcesubstrate and drain-substrate).

For the $\mathrm{I}_{\mathrm{DS}}$ current generator, the mathematical model developed according to the charge control analysis can be assumed to be valid, particularly in analysis problems and first approximation design:

$$
\begin{aligned}
& I_{D S}=\mu_{n} \frac{W}{L} C_{o x}^{\prime}\left[\left(V_{G S}-V_{T}\right)-\frac{V_{D S}}{2}\right] V_{D S} \quad \text { for } V_{D S}<V_{G S}-V_{T} \\
& I_{D S}=\mu_{n} \frac{W}{L} C_{\text {ox }}^{\prime}\left(V_{G S}-V_{T}\right)^{2} \quad \text { for } V_{D S} \geq V_{G S}-V_{T}
\end{aligned}
$$

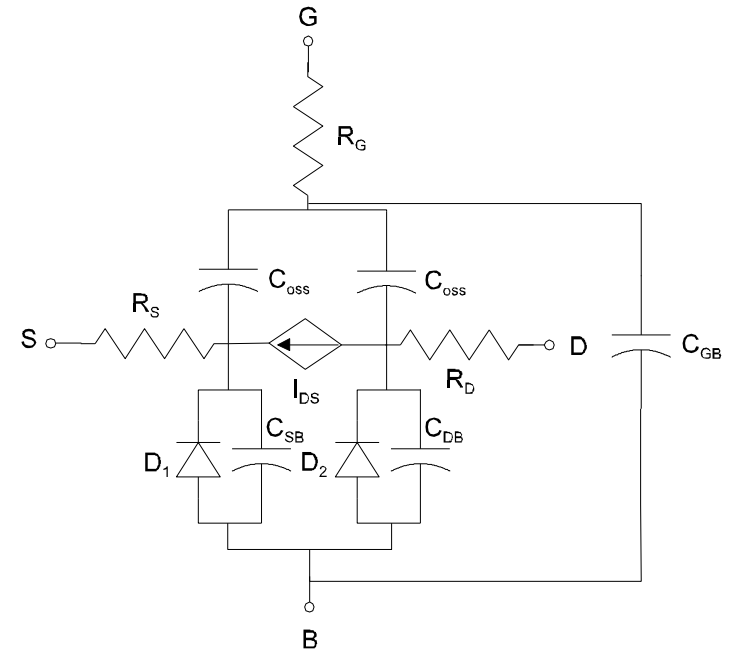

Figure 3. Equivalent circuit of n-channel MOSFET.

Where $\mu_{\mathrm{n}}$ is the electron mobility, $\mathrm{W}$ the MOSFET depth, $\mathrm{L}$ the channel length, $\mathrm{C}_{\mathrm{ox}}^{\prime}$ the gate oxide capacitance per unit area and $\mathrm{V}_{\mathrm{T}}$ the threshold voltage [23-25].

Fig. 4 shows the MOSFET symbol, which refers to BSIM4 model.

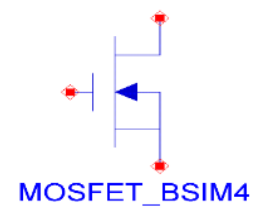

Figure 4. MOSFET symbol.

\section{CNTFET noise model}

Regards to noise model, in [26] we have proposed a compact noise model of CNTFET, and therefore we suggest the reader to consult this paper.

Fig. 5 shows the proposed CNTFET noise model, including five different noise sources.

which are [26]:

\section{1) Thermal noise of $R_{G}$}

The gate resistance $R_{\mathrm{G}}$, implemented as a lumped element with a small value $(\sim 2 \Omega)$, produces a thermal noise, whose power spectral density (PSD) is:

$$
\mathrm{S}_{\mathrm{Th}, \mathrm{RG}}=4 \mathrm{kT} / \mathrm{R}_{\mathrm{G}}
$$




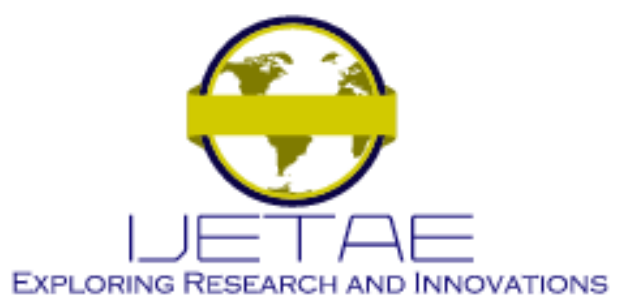

International Journal of Emerging Technology and Advanced Engineering

Website: www.ijetae.com (E-ISSN 2250-2459, Scopus Indexed, ISO 9001:2008 Certified Journal, Volume 11, Issue 07, July 2021)

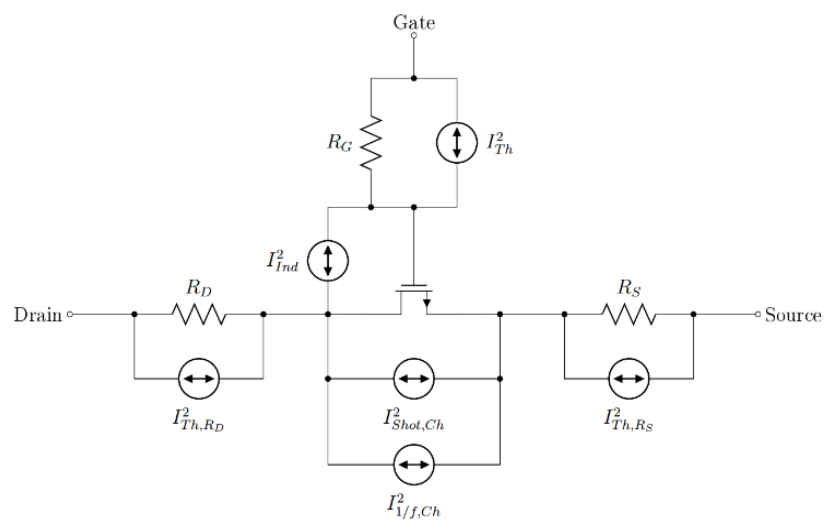

Figure 5. Our CNTFET noise model [26].

\section{2) Thermal noise of $R_{S}$ and $R_{D}$}

The tube end-regions highly doped show high resistances $R_{S}$ and $R_{D}(\sim \mathrm{k} \Omega)$, and their contribution to the power spectral density is in agreement with Eqn. (4).

\section{3) Channel thermal noise and shot noise}

Conventional noise theory for long-channel devices [27] describes the power spectral density of drain noise as:

$$
\mathrm{S}_{\mathrm{Th}, \mathrm{Ch}}=4 \mathrm{kT} \gamma \mathrm{g}_{\mathrm{d} 0}
$$

being $\mathrm{g}_{\mathrm{d} 0}$ the channel conductance at $\mathrm{V}_{\mathrm{DS}}=0 \mathrm{~V}$.

The parameter $\gamma$ is the so-called white noise gamma factor, depending on the operating status of the device and it is equal to $2 / 3$ when CNTFET operates in saturation region.

This classical theory is not satisfactory for white noise in short-channel devices. In these devices it is necessary to consider a white noise gamma factor equals to 2 or 3 [28].

In ballistic devices the carrier flow of charge carriers is hindered by the potential barrier near the source end, and it follows the Poisson statistics, producing shot noise [29]. Moreover it is possible that there is a correlation between successive injection events [30], resulting in a reduction of noise power spectral density, below the value of $2 \mathrm{qI}_{\mathrm{DS}}$.

The resulting suppressed channel shot noise can be expressed as:

$$
\mathrm{S}_{\text {Shot,Ch }}=2 \mathrm{q} \mathrm{I}_{\mathrm{DS}} \cdot \mathrm{F}\left(\mathrm{I}_{\mathrm{DS}}\right)
$$

where $\mathrm{F}\left(\mathrm{I}_{\mathrm{DS}}\right)$, i.e. depending on $\mathrm{I}_{\mathrm{DS}}$, is called Fano factor. Its value is between 0 and 1 .

The value of $\mathrm{F}$ can be taken from empirical graph in literature [28][31].
We considered the worst case condition, i.e. $\mathrm{F}=1$, having considered successive injection events completely uncorrelated.

\section{4) Flicker noise}

The description of this noise is well explained in the literature [32]. According to the empirical law of Hooge [33], we considered the flicker noise in CNTFETs, whose power spectral density is:

$$
\mathrm{S}_{1 / \mathrm{f}, \mathrm{Ch}}=\mathrm{A}_{\mathrm{H}}\left(\frac{\mathrm{I}_{\mathrm{DS}}^{2}}{\mathrm{f}}\right)=\left(\frac{\alpha_{\mathrm{H}}}{\mathrm{n}}\right)\left(\frac{\mathrm{I}_{\mathrm{DS}}^{2}}{\mathrm{f}}\right)
$$

From Eq. (7) $A_{H}$ is the ratio of the material-dependent Hooge constant, $\alpha_{H}$, and the number of carriers $n$ in the channel. We have chosen the value of $\alpha_{\mathrm{H}}$ equal to $10^{-4}$, that is a standard number for un-optimized semiconductor [33].

\section{5) Channel-induced gate noise}

Another type of intrinsic noise that should be considered in CNTFETs is the channel-induced gate noise, whose power spectral density can be described as [27]:

$$
\mathrm{S}_{\text {Ind }}=4 \mathrm{kT} \delta\left(\frac{\omega^{2} \mathrm{C}_{\mathrm{GS}}^{2}}{5 \mathrm{~g}_{\mathrm{d} 0}}\right)
$$

For ballistic devices we have assumed $\delta$ equal to $4 / 3$, considering no type of correlation between noise sources.

Moreover we have not considered the noise sources due to CNT-metal contact Schottky barrier, because our model has been structured for CNTFETs which have no Schottky contacts.

\section{BASIC CURRENT MIRROR CIRCUIT}

The basic current mirror is the keystone of the current mirror circuits and it consists in just two active component as shown in Fig. 6.

In this circuit the reference current is injected by the current generator on the far left side, the two active devices mirror this current on the output, on the right side. The constant voltage generator is plug in series to the output to force the output voltage. The AC voltage generator is used to obtain the output resistance at various frequencies.

We ran fist a static simulation to measure the output behavior of the circuit when the output if forced at various voltages. We first plot ratio of the output current to the input current, since in a current mirror it should be 1 . 


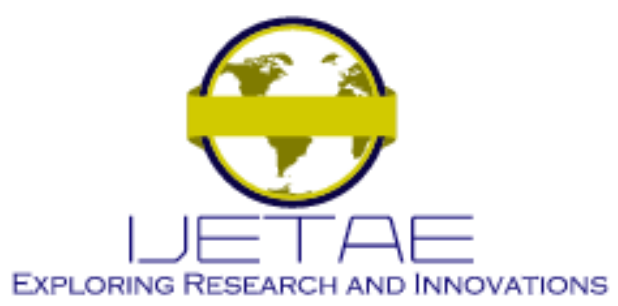

International Journal of Emerging Technology and Advanced Engineering

Website: www.ijetae.com (E-ISSN 2250-2459, Scopus Indexed, ISO 9001:2008 Certified Journal, Volume 11, Issue 07, July 2021)

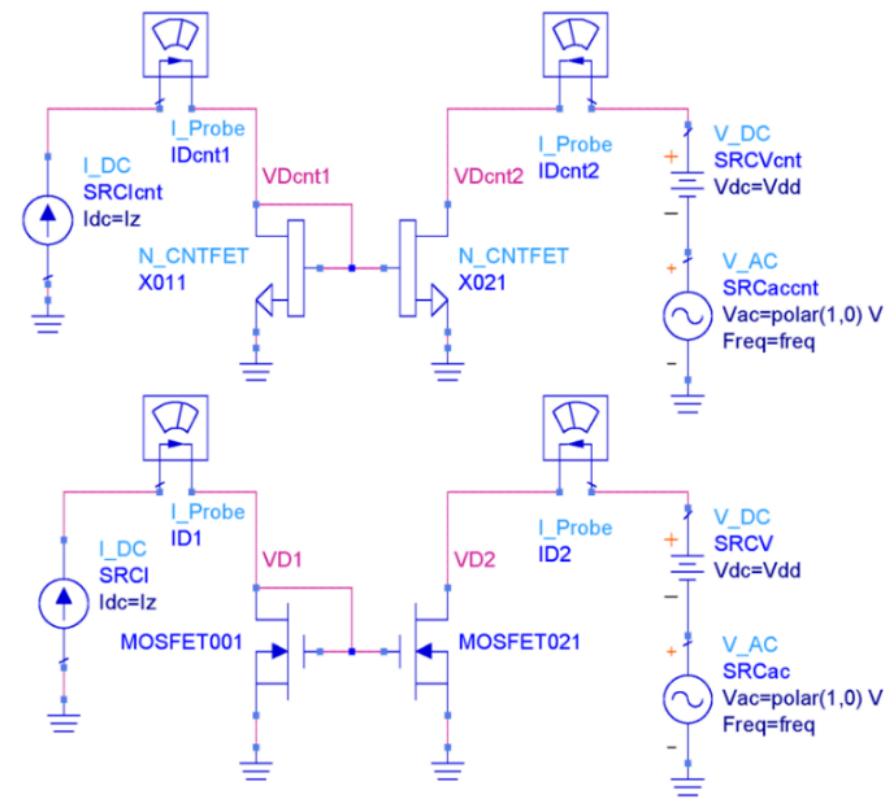

Figure 6. Basic current mirror: on top the CNTFET version, on bottom the MOS version.

In Fig. 7 we present the obtained results for CNTFET and MOS circuit having considered three input currents, 1 $\mathrm{uA}$ (in red), $10 \mathrm{uA}$ (in blue) and $100 \mathrm{uA}$ (in violet). This scheme will be repeated in all following analysis and therefore we will no more stress this.

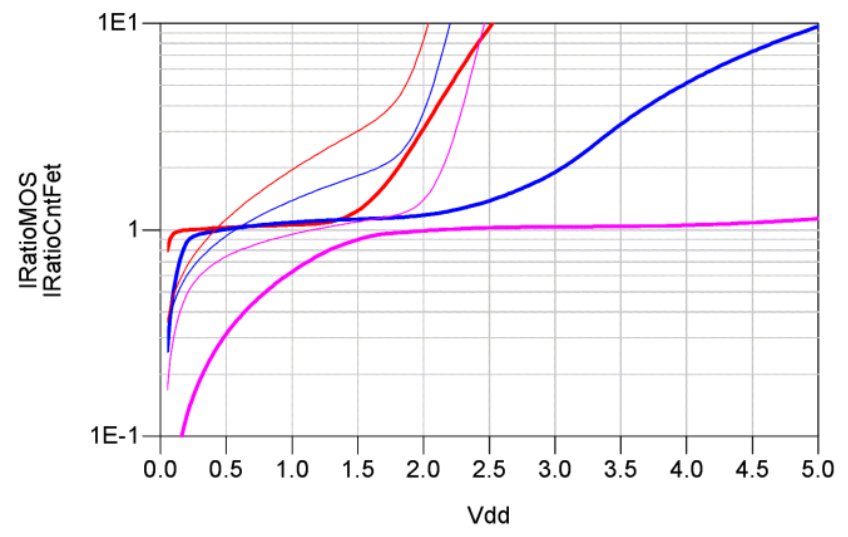

Figure 7. Ratio of the output current divided to the input current. For the CNTFET circuit the curves are bold lines, while for the MOS circuit the curves are thin lines.
From Fig. 7 it is easy to notice that for the CNTFET the ratio is near to 1 for a larger interval of output voltage values, indeed for the MOS circuit the ratio is not stable near the value of 1 .

In the CNTFET case the $1 \mathrm{uA}$ current the ratio is stable from $0.1 \mathrm{~V}$ to $1.5 \mathrm{~V}$, the $10 \mathrm{uA}$ has a good output voltage interval between $0.3 \mathrm{~V}$ and $2.5 \mathrm{~V}$, while the $100 \mathrm{uA}$ current has a ratio near 1 at voltages greater than $1.5 \mathrm{~V}$.

Fig. 8 shows the differential output resistance of the circuit, defined as the derivative of the I-V output static curves.

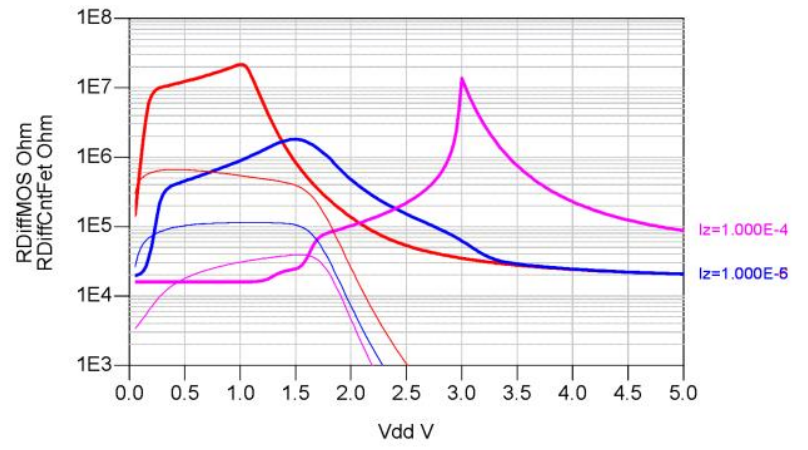

Figure 8. Differential output resistance of the current mirror circuits. Lines as in Fig. 7.

Here we observe that the higher resistance values are in the same intervals where the current ratio is near 1 , as expected. Moreover we observe that the CNTFET circuit has almost always an higher output resistance than the MOS circuit.

In the second simulation we studied the frequency behaviour of the output admittance for small signal in linearized approximation and the obtained results are in Figs. 9 and 10 (output voltage $=1 \mathrm{~V}$ all the currents).

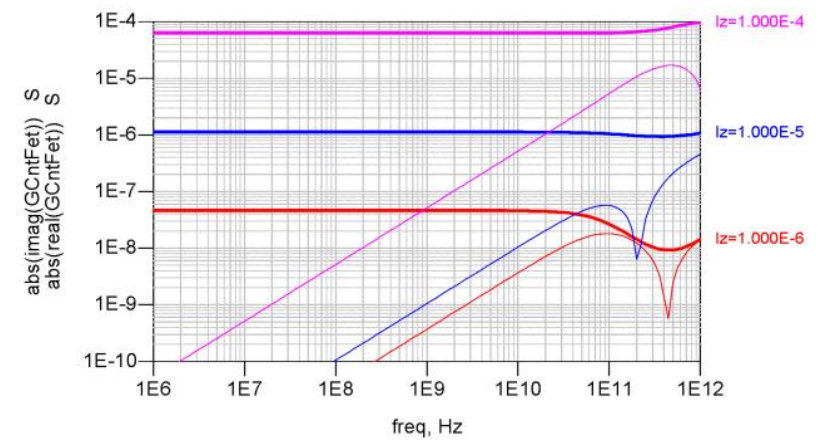

Figure 9. Differential output admittance for the CNTFET circuit, values in Siemens. The real part is in bold lines, the imaginary part in thin lines. 


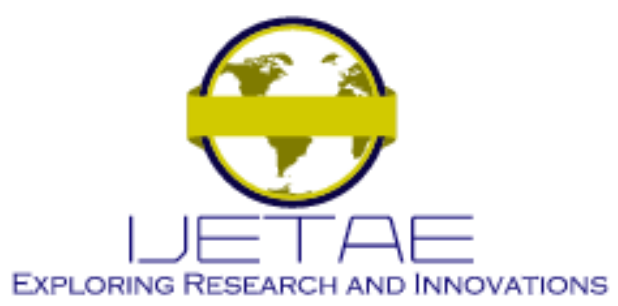

International Journal of Emerging Technology and Advanced Engineering

Website: www.ijetae.com (E-ISSN 2250-2459, Scopus Indexed, ISO 9001:2008 Certified Journal, Volume 11, Issue 07, July 2021)

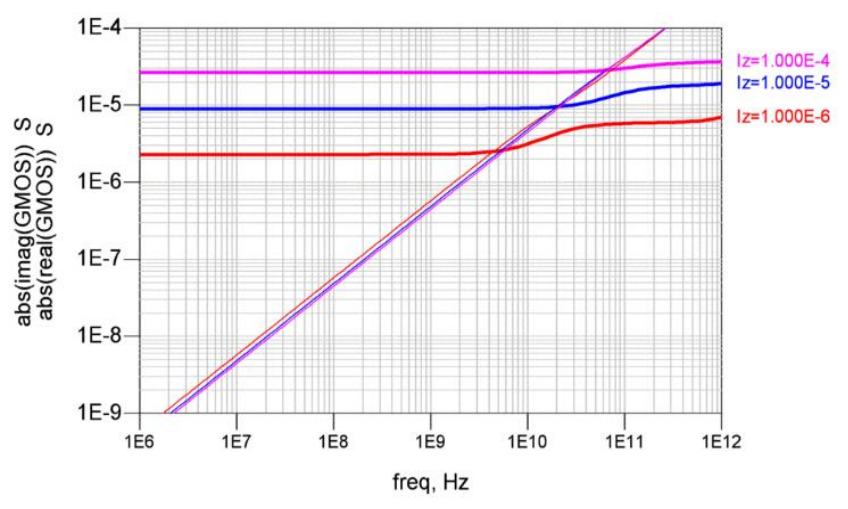

Figure 10. Differential output admittance for the MOS circuit, values in Siemens. The real part is in bold lines, the imaginary part in thin lines.

We can observe that while the real part is almost independent from the frequency, the imaginary part (at frequency lower than $100 \mathrm{GHz}$ ) is just proportional to the frequency, so that, at lower frequency, the differential output circuit could be represented as a parallel of a resistor, a capacitor and the current generator.

As third analysis we present the noise simulations at output voltage $1 \mathrm{~V}$.

Fig. 11 shows the spectral density of the output noise current for both CNTFET and MOS at different currents.

We can see higher noise in the CNTFET circuit in almost all cases, but over $1 \mathrm{GHz}$ it is no more than three times higher, as shown in Fig. 12. In the case of $100 \mathrm{uA}$ current, the noise in lower for the CNTFET circuit.

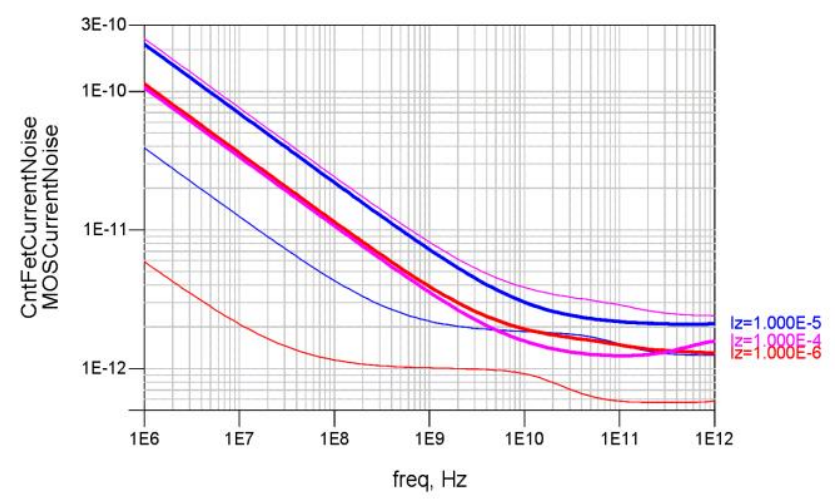

Figure 11. Spectral density of the output noise current for the CNTFET and for the MOS circuit, values in $\mathrm{A} \mathrm{Hz}^{-1 / 2}$. Lines as in Fig. 7.

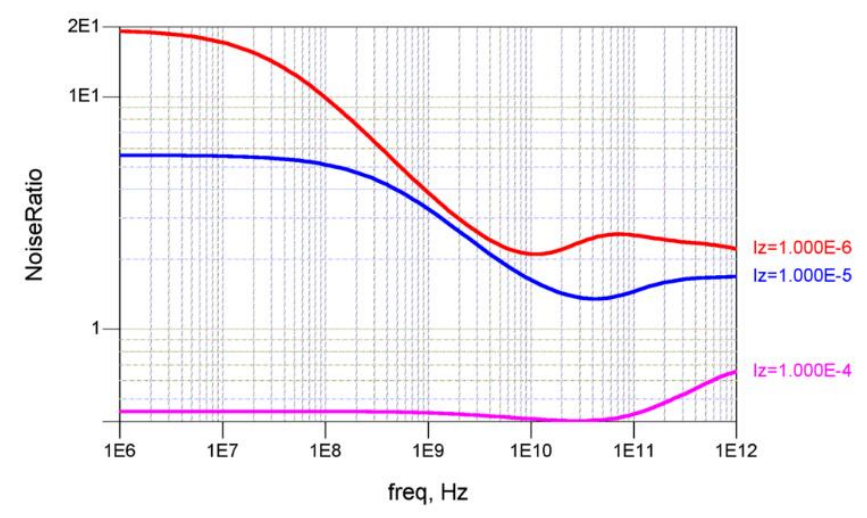

Figure 12. Ratio of the noise current spectral density of the CNTFET circuit divided by the noise current spectral density of the MOS circuit.

We also calculate the spectral density of noise current for the component coming from the flicker, the shot and the thermal noise coming from input and output devices for the CNTFET circuit.

Except the case of the $100 \mu \mathrm{A}$ current, devices contribute evenly to the output noise in the lower frequency range. Since the main idea of the current mirror is just mirroring current, it was easy to understand how the noise current on the input branch is mirrored in the output branch when the circuit is properly working.

In the CNTFET, compared to BSIM4 MOS model, for frequencies below $10 \mathrm{GHz}$ the main contribution is the flicker noise which largely dominates for its $1 / \mathrm{f}$ dependence. For frequency over $10 \mathrm{GHz}$ the main contributor are the shot noise and the thermal noise.

Since the thermal noises is proportional to the resistances, its reduction requests a better control of the various parasitic resistances, always considering that the limit for channel resistance is the quantum limit.

We also observe that the effect of correlation between channel current noise and the current noise induced in the gate, has a negligible effect on the overall result, as predicted in [27].

\section{CONCLUSION}

We have presented a simulation study of a basic current mirror based on CNTFET, comparing it with the same using MOS device and showing the output I-V curves, the output differential conductances at various output voltages, the output admittance at various frequencies and the spectral density of output noise current. 


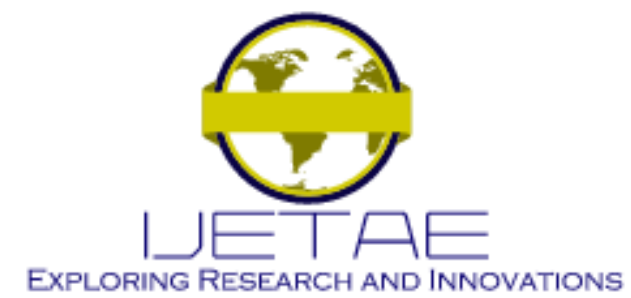

International Journal of Emerging Technology and Advanced Engineering Website: www.ijetae.com (E-ISSN 2250-2459, Scopus Indexed, ISO 9001:2008 Certified Journal, Volume 11, Issue 07, July 2021)

For reference current of $1 \mu \mathrm{A}$ and $10 \mu \mathrm{A}$ the output static and dynamic characteristics are better in the case of CNTFET, but for all cases the output noise current is always higher for the CNTFET than for the MOS.

The output noise for CNTFET is no more than three times higher $(10 \mathrm{~dB})$ than for the MOS, but at some frequency and current we foresee no more than two $(6 \mathrm{~dB})$ times higher.

\section{REFERENCES}

[1] Perri, A.G., and R. Marani, R. 2017. CNTFET Electronics: Design Principles. Ed. Progedit. Bari, Italy.

[2] Jafarbeglou, M., Abdouss, M., and Ramezanianpour, A.A. 2015. Nanoscience and Nano Engineering in Concrete Advances A Review. International Journal of Nanoscience and Nanotechnology, 11(4), 263-273.

[3] Marani, R., and Perri, A.G. 2009. CNTFET modelling for Electronic Circuit Design. ElectroChemical Transactions, 23(1), 429-437.

[4] Gelao, G., Marani, R., Diana, R., and Perri, A.G. 2011. A SemiEmpirical SPICE Model for n-type Conventional CNTFETs. IEEE Transactions on Nanotechnology, 10(3), 506-512.

[5] Marani, R., and Perri, A.G. 2011. A Compact, Semi-empirical Model of Carbon Nanotube Field Effect Transistors oriented to Simulation Software. Current Nanoscience, 7(2), 245-253.

[6] Marani, R., and Perri, A.G. 2012. A DC Model of Carbon Nanotube Field Effect Transistor for CAD Applications. International Journal of Electronics, 99(3), 427- 444.

[7] Marani, R., Gelao, G., and Perri, A.G. 2012. Comparison of ABM SPICE library with Verilog-A for Compact CNTFET model implementation. Current Nanoscience, 8(4), 556-565.

[8] Marani, R., Gelao, G., and Perri, A.G. 2013. Modelling of Carbon Nanotube Field Effect Transistors oriented to SPICE software for A/D circuit design. Microelectronics Journal, 44(1), 33-39.

[9] Marani, R., and Perri, A.G. 2016. Analysis of CNTFETs Operating in SubThreshold Region for Low Power Digital Applications. ECS Journal of Solid State Science and Technology, 5(2), M1-M4.

[10] Marani, R., and Perri, A.G. 2016.. A De-Embedding Procedure to Determine the Equivalent Circuit Parameters of RF CNTFETs, ECS Journal of Solid State Science and Technology, 5(5), M31-M34.

[11] Verilog-AMS language reference manual. 2014.Version 2.2.

[12] Marani, R., and Perri, A.G. 2016. A Simulation Study of Analogue and Logic Circuits with CNTFETs. ECS Journal of Solid State Science and Technology, 5(6), M38-M43.

[13] Marani, R., and Perri, A.G. 2016. A Comparison of CNTFET Models through the Design of a SRAM Cell. ECS Journal of Solid State Science and Technology, 5(10), M118-M126.

[14] Gelao, G., Marani, R., Pizzulli, L., and Perri, A.G. 2015. A Model to Improve Analysis of CNTFET Logic Gates in Verilog-A-Part I: Static Analysis. Current Nanoscience, 11(4), 515-526.

[15] Gelao, G., Marani, R., Pizzulli, L., and Perri, A.G. 2015. A Model to Improve Analysis of CNTFET Logic Gates in Verilog-A-Part II: Dynamic Analysis. Current Nanoscience, 11(6), 770-783.
[16] Marani, R., and Perri, A.G. 2018. Design and Simulation Study of Full Adder Circuit based on CNTFET and CMOS technology by ADS, ECS Journal of Solid State Science and Technology, 7(6), M108-M122.

[17] Marani, R., and Perri, A.G. 2020. Techniques to improve the Performance in the CNTFET-based Analogue Circuit Design. ECS Journal of Solid State Science and Technology, vol. 9(3).

[18] Marani, R., and Perri, A.G. 2020. Impact of Technology on CNTFET-based Circuits Performance. ECS Journal of Solid State Science and Technology, vol. 9(5).

[19] Raychowdhury, A., Mukhopadhyay, S. and Roy, K. 2004. A circuitcompatible model of ballistic Carbon Nanotube Field Effect Transistors, IEEE Transactions on Computer-Aided Design of Integrated Circuits and Systems, 23(10), 1411-1420.

[20] Prégaldiny, F., Lallement, C. and Kammerer, J.K. 2006. Designoriented compact models for CNTFETs. Proceedings of International Conference on Design and Test of Integrated Systems in Nanoscale Technology, Tunis, Tunisia, 34-39.

[21] Prégaldiny, F., Lallement, C., Diange, B., Sallese M. and Kammerer, J.K. 2007. Compact Modeling of Emerging Technologies with VHDL-AMS. In Huss, S.A. (ed). Advances in Design and Specification Languages for Embedded Systems. Dordrecht: Springer Netherlands.

[22] Datta, S. 1995. Cambridge Studies in Semiconductor Physics and Microelectronic Engineering 3. Electronic Transport in Mesoscopic Systems, New York: Cambridge University Press.

[23] Allen, P.E., and Holberg, D.R. 2013. CMOS Analog Circuit Design, Oxford University Press.

[24] Kashti, V.V., and Monica, R. 2014. Performance Analysis of CMOS Comparator And CNTFET Comparator Design. Int. J. Res. Eng. and Technol., 3(4), 862-866.

[25] http://bsim.berkeley.edu/models/bsim4/

[26] Marani, R., Gelao, G., and Perri, A.G. 2017. A Compact Noise Model for C-CNTFETs. ECS Journal of Solid State Science and Technology, 6(4), M118-M126.

[27] Van der Ziel, A. 1986, Noise in Solid State Devices and Circuits. New York: Wiley.

[28] Landauer, G.M. and Gonzalez, J.I. 2012. A compact noise model for carbon nanotube FETs. Proceedings of 2012 International Semiconductor Conference Dresden-Grenoble (ISCDG).

[29] R. Navid, R., Jungemann, C., Lee, TH. and Dutton, R.W. 2007. High.frequency noise in nanoscale Metal Oxide Semiconductor Field Effect Transistors, Journal of Applied Physics, 101, 124501.

[30] Betti, A., Fiori, G. and Iannaccone, G. 2009. Shot Noise suppression in quasi-one-dimensional Field Effect Transistors. IEEE Transactions on Electron Devices, 56(9), 2137-2143.

[31] Landauer, G. M. and Gonzalez, J.L. 2012. Carbon nanotube FET process variability and noise model for radiofrequency investigations. Proceedings of 2012 12th IEEE International Conference on Nanotechnology (IEEE-NANO), Birmingham, UK.

[32] Lin, Y.M., Appenzeller, J., Knoch, J., Chen, Z. and Avouris P. 2006. Low-frequency Current Fluctuations in Individual Semiconducting Single Wall Carbon Nanotubes. Nano Letters, 6(5), 930-936.

[33] Hooge, F.N. 1994. 1/f noise sources. IEEE Transactions on Electron Devices, 41(2), 1926-1935. 